\title{
UMA VIAGEM GEOGRÁFICA PELA LITERATURA: UMA EXPERIÊNCIA COM UM CLUBE DO LIVRO NA GEOGRAFIA ESCOLAR
}

\author{
A geographical journey for literature: an experience with a book club in School \\ Geography
}

\author{
Leonardo Pinto dos Santos \\ Professor da Rede Estadual de Ensino do Rio Grande do Sul \\ Doutorando da Universidade Federal de Santa Maria \\ leonardoufsm@hotmail.com
}

Artigo enviado para publicação em 05/11/2017 e aceito em 15/04/2018

DOI: $10.12957 /$ tamoios.2018.31135

\section{RESUMO}

O presente artigo apresenta uma experiência de ensino de Geografia Escolar a partir da atividade de um clube do livro. Ela ocorreu no ano de 2017 em uma instituição de educação básica, com o objetivo de trabalhar com o conceito de Espaço Mentalmente Projetado (EMP), tendo sido implementada em caráter voluntário com estudantes do sexto ao nono ano dos Anos Finais do Ensino Fundamental. A ideia partiu do pressuposto de se potencializar a leitura da realidade a partir do debate entorno de obras literárias que apresentam como plano de fundo diferentes contextos do nosso Espaço Geográfico. Os resultados obtidos indicaram que o contato com a Literatura auxilia na compreensão do Espaço Geográfico, além de otimizar o diálogo entre os atores envolvidos no processo de aprendizagem.

Palavras-chave: Geografia Escolar; Espaço Mentalmente Projetado; Literatura; Clube do Livro.

\begin{abstract}
The present article presents a teaching experience of School Geography from the activity of a book club. It occurred in the year 2017 in a basic education institution, aiming to work with the concept of Mentally Designed Space, and was implemented on a voluntary basis with students from the $6^{\circ}$ to the $9^{\circ}$ year of the Final Years of Elementary Education. The idea was based on the assumption that the reading of reality is enhanced through the debate around literary works that present as background different contexts of our Geographic Space. The results indicated that the contact with the Literature helps in the understanding of the Geographic Space, besides improving the dialogue between the actors involved in the learning process.
\end{abstract}

Keywords: School Geography; Mentally Designed Space; Literature; Book Club. 


\section{O MUNDO DOS LIVROS: UM INÍCIO DE CAMINHADA}

A ideia deste trabalho partiu de uma experiência desenvolvida em uma instituição de ensino pública localizada na região metropolitana de Porto Alegre, Rio Grande do Sul, no decorrer do ano de 2017.

Como professor de Geografia dos Anos Finais do Ensino Fundamental (sexto ao nono ano) e assíduo leitor de diferentes obras literárias, sempre tive como prática nas aulas recomendar e emprestar livros, indicando também outras fontes de leitura para os meus alunos ${ }^{1}$.

Como a partir de 2017 passei a ter a oportunidade de trabalhar na biblioteca da escola com diversos projetos, logo veio a ideia de se montar um grupo de leitura no turno inverso de estudo dos meus alunos, com o intuito de se incentivar a leitura e se debater os contextos históricos em que cada obra foi escrita, um pouco da biografia de cada autor(a) e a Geografia ali permeada.

O que se desenvolveu a partir deste ponto foi o desenrolar de convites de caráter voluntário, que para grata surpresa foram prontamente atendidos. A partir deste momento fui montando um grupo heterogêneo de crianças do sexto ao nono ano, para encontros mensais.

A importância desta pesquisa se insere no contexto de acreditarmos que ninguém nasce leitor, muito menos não leitores. O hábito de leitura nasce e cresce nas experiências de nossas vidas, começando ainda quando bebês, quando adultos nos contam histórias, uma das formas de se fortalecer vínculos afetivos.

Diferentes momentos de nossas vidas nos tornam leitores ou não leitores, sendo que a escola puxa para si um papel de destaque para essa conquista ou não de novos leitores. O hábito de leitura entre os brasileiros ainda é baixo, sendo a razão disso as mais variadas, desde o preço inacessível deste tipo de material para grande parte da população, bem como destaca Galeano (2014, p.152) “os livros não precisam ser proibidos pela polícia: os preços já os proíbem”, até o pouco incentivo a essa ação por parte de familiares e professores.

O incentivo à leitura, com potencial para aprendizagem da História e da Geografia na escola, ganha ainda mais relevo a partir de pesquisas como do Instituto Paulo Montenegro e da Organização Não Governamental Ação Educativa que revela que $38 \%{ }^{2}$ dos estudantes do ensino superior são analfabetos funcionais, ou seja, de cada três estudantes do ensino superior, um não domina habilidades básicas de leitura e escrita.

A pesquisa Retratos da Leitura no Brasil (2016) destaca uma situação ainda mais alarmante do leitor no Brasil, indicando que pelo menos $30 \%{ }^{3}$ dos entrevistados nunca comprou um livro, sendo que para $67 \%$ da população, não existiu uma figura como um professor(a) ou outro adulto que a incentivasse a leitura em qualquer ponto de sua trajetória como sujeito.

Antes de continuarmos, e, como estamos falando em Literatura, vou descrever uma história que dará o entrelace do nosso ideário com este projeto de se montar um grupo de leitura.

Quem conta essa nossa primeira história (pouco longa, mas necessária ser replicada na integra) é Madalena Freire (1993, p.165-167):

Aqui tem uma história. Aguentam ouvir?

É uma história cujo conteúdo está inserido na apropriação-pergunta sobre de onde vim. Que todos nós não paramos de fazer. "O que é que faço? Para onde vou? Quem sou? O que é que quero?" É a história da Eliane, aluna minha, da Vila Helena, uma favela de Carapicuíba, São Paulo, capital.

Eliane era uma criança de cinco anos que não parecia ser gente. Ela chegava à escola maltrapilha - e não era por falta de roupa ou por ser favelada - toda suja, cabelo desgrenhado, se arrastava pelo chão, não sentava à mesa para trabalhar. Vivia no chão. E na sua parte mais suja, perto do lixo que havia na classe. 
Seu olhar não tinha fundo. Era um olhar solto. Vagueante. Procurava o contato com Eliane pelo olhar, e ele era solto, não tinha fundo embora sua base fosse o chão. $\mathrm{O}$ chão era a sua geografia mais íntima, perto do lixo.

Fiz de tudo. "Eliane, vambora daqui, olha aqui um banco, senta aqui, blá, blá, blá". No máximo do apogeu da minha conquista, ela sentou um segundo no banco e voltou imediatamente para o chão, perto do lixo. E eu observando. Observando. Registrando e perguntando: "Que diabo será? o que acontece? por quê?". Tinha umas hipóteses, mas não era por ali, que negócio tão forte é esse? O que é isso? Nada. Nada mesmo. Decidi descer para o chão. Era a única maneira de dizer: "Eliane, estou aqui, no chão, neste espaço com você". Não pense não que parei a classe todinha para cuidar só de Eliane. Não. Tinha que fazer isso ao mesmo tempo, com pensamento articulado de tempo, em que eu podia descer para o chão e tempo em que não podia. Sentada no chão, perto do lixo, igual.

Comecei a organizar o espaço do chão com Eliane. Organizar no sentido de não haver nenhum elemento estranho - no sentido da limpeza, do não-lixo. Ou começava a partir do que ela conhecia, ou não poderia construir nada de novo com ela. Comecei a limpar o chão. - A Eliane, põe esta terra mais lá, aqui tá bom... e tal. E comecei a planejar atividades - desenho, construção, escrita, construção da pipa, a construção dos brinquedos, ali no chão. Marcava um traço, delimitava um espaço, "nossa mesa é aqui", e pronto.

Ali ela iniciou, levemente, a realizar uma atividade. Pegava um palito, desenhava uma coisa, conversava, comentava. Imediatamente desfazia. Ela foi se fazendo cada vez mais presente, trocávamos os palitinhos, fazíamos pontas neles, variávamos, fazíamos outro, até que chegou o papel.

Papel posto, lápis introduzido, caneta... junto com o papel uma madeira, não mais o piso. E com o papel começou o segundo grande movimento. O desenho começou a existir de leve, mas um segundo grande movimento iniciou-se. Pegava um papel, amarrotava e atirava para o lixo. Este movimento de lançar, várias e várias vezes, o papel no lixo foi sendo observado. Fui percebendo que esse movimento era de um ódio mortal. Ao mesmo tempo tinha alguma coisa de amor nele. Eu não sabia, mas eu só via que aquilo tinha uma história! E ia tentar decifrá-la!

O lixo e este gesto passaram a ser os signos de Eliane. Este arremessar com ódio misturado com amor... Desenvolvi várias situações: - você consegue lançar com mais força, com menos força? Em câmera lenta? Nada, nada tinha ressonância, só aquele arremessar violento.

Planejei reapresentar, trazer a situação do conflito para ser pensada, socializada, para poder deflagrar a construção do conhecimento. Neste sentido, o educador é um artista, porque lida com a leitura do inusitado e com essa reapresentação cotidianamente.

Decidi sem saber, confesso, que iria reapresentar para Eliane aquele seu gesto de ódio e amor no lançar objetos ao lixo. Como? Aonde? Em quê? Que hora? De que maneira? O que é que eu invento? Com todas estas questões, fiquei de olho aberto, procurando uma atividade em que pudesse atuar.

Ela tinha um jogo de casinha, onde era mãe. Ninava, ninava, ninava e, depois, como se estivesse de lua, repetia aquele mesmo gesto. Onde estivesse. Eu pensei: é ali. É ali que vou ter que buscar para pegar. Propus uma atividade de construção com massa, barro, e ela trabalhando, no chão, ainda, com aquela madeira e fez, nesse dia, um boneco.

Quando ela fez o boneco - e eu por perto - senti que estava na hora de entrar em cena. Cheguei perto, porque tinha absoluta certeza de que, rapidinho, aquele boneco iria ser esmagado. Aproximei-me, e quando ela foi pegando para fazer isso, mais do que depressa avancei em cima dela, carreguei-a e fiz o mesmo movimento: o de jogá-la no lixo.

E o medo? E a dúvida? E a minha agressividade? Meu Deus o que é que estou fazendo? Que ato será esse de amor e ódio, o que é isso? Eu não sabia.

Quando repeti o mesmo movimento, o mesmo gesto, perguntei: - Você quer, Eliane, você quer que eu lhe jogue no lixo? - ela aterrissou o olhar. Pela primeira vez vi o fundo de seu olho, e ela disse: -não, eu não quero que você me jogue no lixo.

Sentamos no chão. Eu, em pandareco, desfeita, sem ter o rumo, mas tinha claro uma conquista: vi o fundo do olho! Ela pegou em alguma coisa de sua história. E a primeira 
coisa que ela me disse foi: - Você sabia que, quando eu nasci, minha mãe jogou eu na lata do lixo? você sabia que quem me pegou foi minha vó?

Se eu já estava em pandareco, naquele momento já não conseguia me levantar. Em silêncio, as duas, como se as tivesse vendo num videoteipe de nascimento. Dei um tempo. Falei para ela: - Que bom, Eliane, você ter dito isso hoje. Eliane, mãe perde cabeça. Mãe ama e odeia, Eliane, mas é mãe... E ela começou a contar da avó, começou a contar da mãe. Antes, essa mãe nunca tinha sido nomeada. Na ficha da matrícula, a mãe era a avó. Não existia mãe.

E continuei: - Mas você já saiu do lixo, você não está mais no lixo, você pode tomar banho, se limpar, se vestir, se pentear. Você está viva, Eliane! Veja quanto você já trabalhou aqui mesmo no chão... Tem muito trabalho, Eliane, pra você continuar fazendo e vivendo... Por obra e graça do Espírito Santo tinha um sabonete na minha bolsa. Peguei e disse: - Isso aqui é pra você tomar um banho! O banho do recémnascido. - E venha para a escola!. Quem me ouve aqui pensa que eu estava muito segura...

Saí de lá, acabou o dia e me tranquei no diabo de um carro velho que eu tinha e chorei. Fui chorando caminho afora e não parava de chorar, e chorei a noite toda. Meu Deus! Foi só naquele momento que percebi que fui parteira de Eliane. Quem tem a confiança de que ela voltará amanhã? E se ela não voltar? No outro dia chegou, abriu a porta. Parecia uma princesa. Cabelo penteado. Cara limpa. Ninguém via a cor da Eliane antes. Cara limpa, mostrando pele. Cheiro. E pra mim, a imagem era única. Tudo que estava ao redor desaparecera, ofuscara-se. Eliane vindo, nascida, nova para uma outra vida.

Eliane chegou e me disse: - Onde é o meu lugar na mesa?

A partir deste dia começou seu trabalho na mesa e começou a trazer a mãe. Para o lanche, para o café, para ver o álbum, para ver sua pasta. Assumiu o amor e ódio na relação. Chega, pelo amor de Deus, que meu coração está em frangalhos.

A prática de leitura não pode ser um gene recessivo nas salas de aula do nosso Brasil, ela precisa ser um dos dominantes. Este é um dos caminhos para que o chão perto do lixo não seja a Geografia mais íntima de nenhuma Eliane, de nenhum João ou Maria do território que chamamos de pátria amada.

Esse é o nosso intuito com essa pesquisa, por acreditarmos que cada ato realizado por nós é político, não podemos nos omitir enquanto professores em simplesmente vencer os conteúdos estipulados pelas normativas oficiais.

Qualquer dos componentes curriculares podem dar o balanço árido do número de mortos, refugiados, presos, desaparecidos, etc., mas quem dará o balanço dos que padecem de fome em um mundo que produz alimento suficiente; dos que morrem de sede pelo uso indiscriminado de setores dominantes da economia; quem dará o balanço daqueles que desaparecem nas águas do Mar Mediterrâneo na busca de uma condição mínima de vida; dos que viram poeira nos áridos palcos de conflitos sociais regados a interesses petrolíferos ou de outra riqueza que enobrece e empobrece o país? Quem e como dar sentido político a estes conteúdos que estão tão evidentes em um mundo regido pelo capital e não pelo bem-estar coletivo? O mundo das letras é um belo caminho que podemos trilhar.

Como o professor Kaercher (2004, p.298) destaca, "conhecimentos altamente políticos e ideológicos, mas que são tratados pela escola com uma aura de neutralidade e de simples informação". Carregamos em nossa essência docente, que a Literatura pode auxiliar nesse movimento de trabalhar conhecimentos com alto grau de teor político, enriquecendo o vocabulário e as possibilidades de ação do sujeito aluno, sendo tangencial a história contata em cada obra, temas como a ética, a política, a comunicação, a guerra, a paz, os direitos de populações minoritárias, a justiça, a fome, a sede, a memória, entre tantos outros. 
Vemos na Literatura um grande potencial para se trabalhar o conceito de Espaço Mentalmente Projetado (COSTELLA, 2008; 2017; SANTOS, 2015; 2017) e, que possui em sua essência um outro olhar sobre o Espaço Geográfico e para com o próximo.

Além destes pontos, a leitura eleva o potencial de expressão das crianças, seja oralmente ou na forma escrita, e, no momento em que se monta um grupo de leitores criam-se laços que permitem chegar ao "fundo do olho" do próximo, como na história real contata por Madalena Freire.

\section{OS CAMINHOS PERCORRIDOS: por um abc geográfico}

O trabalho envolveu um grupo de treze alunos, de diferentes faixas etárias e experiências de vida, sendo dois do sexto ano, um do sétimo, quatro do oitavo e seis do nono ano do Ensino Fundamental Anos Finais - sendo oito meninas e cinco meninos -, que de forma voluntária se mostraram interessados pela proposta de se trabalhar no turno inverso as suas aulas com obras literárias indicadas pelo professor de Geografia.

A metodologia empregada foi a investigação-ação (IA) (COUTINHO; SOUSA; DIAS; BESSA; FERREIRA; VIEIRA, 2009) que se aproxima das correntes pedagógicas que buscam o "aprender a aprender", dentre os quais temos expoentes como Jean Piaget, Lev Vygotsky e Henri Wallon. Estes pesquisadores pensam que o conhecimento se dá a partir de uma ação ativa do sujeito envolvido, não sendo o aluno uma tábula rasa nem que este apresente estruturas de conhecimento pré-formatadas já quando do seu nascimento. Desta forma, o desenvolvimento não ocorreria a partir de um processo de maturação e este sujeito não teria uma relação passiva frente ao conhecimento, mas sim, agiria a partir de seus interesses com o mundo que o circunda tentando resolver os anseios que de alguma forma o desequilibra.

$\mathrm{Na}$ escola chamada de tradicional, o processo de ensino e aprendizagem está centrado no professor, que se preocupa mais em "o que e como se ensina", do que em "como se aprende", uma herança que perpassa no Brasil com a chegada dos jesuítas em 1549 e pendura até os dias atuais em muitos recantos de nosso território.

A partir da investigação-ação, temos o professor como mediador da relação entre o aluno e o mundo real que precisa ser compreendido, não mais temos o professor como mediador entre o conhecimento acumulado e as novas gerações (COUTO, 2017). Desta forma, procuramos superar o dualismo entre a teoria e a prática, sendo que a investigação-ação achou seu "chão" dentro dos processos educativos que possuem como plano de fundo um grupo de professores preocupados com uma outra educação possível.

A IA se caracterizar por um maior dinamismo na forma como professores e alunos encaram a realidade, sendo delineada por uma maior interação social e aproximação da realidade a partir da práxis, ela se mostrou a melhor metodologia a ser empregada nessa pesquisa que busca uma reflexão crítica entorno do Espaço Geográfico a partir da Literatura.

Por ser uma metodologia que vê a figura do professor como um investigador, ela toma corpo em nosso ideário do professor-pesquisador (BECKER; MARQUES, 2012), em que valoriza a prática - sem esquecer a teoria - no intento de uma educação ativa (concepção Construtivista), que além da ação dos sujeitos envolvidos, a investigação-ação apresenta como seu cerne a questão da reflexão, ponto primordial quando pensamos no ato da leitura e da apreensão do que se lê, pensando e transformando as letras lidas em ideias e conceitos que podem/devem ser trabalhados dentro da Geografia Escolar.

A partir deste ponto, foram selecionados vinte e um livros, abordando diferentes realidades e momentos históricos, tendo obras também de um mundo - nem tanto - irreal, pautados em metáforas de países, pessoas e realidades "inexistentes" na história das sociedades.

A seguir, encontram-se listadas as obras oferecidas, com os respectivos autores:

a) 1984. George Orwell; 


\author{
b) Admirável mundo novo. Aldous Huxley; \\ c) A longa marcha: a história do mito fundador da China comunista. Sun Shuyu; \\ d) A memória de todos nós. Eric Nepomuceno; \\ e) Amon: meu avô teria me executado. Jennifer Teege; \\ f) A noite dos generais: os bastidores do terror militar na Argentina. José Meirelles \\ Passos; \\ g) A revolução dos bichos. George Orwell; \\ h) As garotas da fábrica: da aldeia à cidade, numa China em transformação. Leslie \\ T. Chang; \\ i) A vida que ninguém vê. Eliane Brum; \\ j) Despachos do front. Michael Herr; \\ k) É isso que eu faço: uma vida de amor e guerra. Lynsey Addario; \\ 1) Estação Carandiru. Drauzio Varella; \\ m) Na pele de uma Jihadista: a história real de uma jornalista recrutada pelo Estado \\ Islâmico. Anna Erelle; \\ n) O homem que amava os cachorros. Leonardo Padura; \\ o) O pianista. Wladyslaw Szpilman; \\ p) Os miseráveis. Victor Hugo; \\ q) $\mathrm{O}$ zero e o infinito. Arthur Koestler; \\ r) Quarto de despejo: diário de uma favelada. Carolina Maria de Jesus; \\ s) Raízes do conservadorismo brasileiro: a abolição na imprensa e no imaginário \\ social. Juremir Machado da Silva; \\ t) Terra sonâmbula. Mia Couto; \\ u) Um diário do ano da peste. Daniel Defoe.
}

As seguintes obras fazem parte do acervo particular do professor de Geografia e algumas já existiam na biblioteca escolar. No seu contexto, estão histórias que tratam de diferentes espaços ausentes, como Moçambique de Mia Couto e a França de Victor Hugo, a China de Chang e o Vietnã de Herr. Outras mostram uma realidade não tão ausente nem distante ao século XXI, bem como 1984, de George Orwell e O zero e o infinito, de Arthur Koestler.

A partir do primeiro encontro, em que foi separado a obra que cada um leria, ficou acertado que cada aluno apresentaria para seus colegas uma biografia dos autores e como estava organizado espacialmente o mundo quando os mesmos saíram das mentes dos autores e ganharam contornos nas páginas em branco.

Os encontros ocorreram no espaço escolar, no turno inverso, uma vez por mês. Portanto, as crianças tinham este espaço de tempo para fazer a leitura e construir os pontos acertados, como contextualizar para com os outros a vida e visão dos autores. Como há leitores de diferentes ritmos, mais de um aluno acabou lendo além de um livro, sendo que, ficou ao seu encargo a escolha de qual seria apresentado dentro do material lido.

No fim de cada mês, se realizaram dois encontros em dias diferentes de uma mesma semana, e, cada um apresentava suas leituras. Posteriormente faziam a troca dos livros, para recomeçar a atividade com uma nova leitura que poderia ser uma das já comentadas por algum aluno, e que por ventura tenha despertado o interesse de um dos componentes do grupo, ou mesmo, escolhido dentre as opções não selecionadas anteriormente, uma vez que, tínhamos mais obras do que leitores.

Os vinte e um livros foram separados pelo professor, mas os alunos tinham plena liberdade de escolha do seu material de leitura dentro do universo delimitado. 
Essa atividade foi desenvolvida durante quatro meses (julho a outubro) de 2017, sendo possível para cada aluno ter lido e apresentado um mínimo de quatro obras no final dos encontros mensais.

Como professor destes sujeitos, apresentei no final do mês de outubro, no nosso último encontro, as conexões geográficas e históricas que os alunos haviam desenvolvido, além de alguns pontos que haviam passado em branco por parte deles.

O trabalho se mostrou interessante, uma vez que, temas presentes nas obras construíram uma ponte para tantos outros assuntos, como a condição do proletariado no século XXI; o uso de entorpecentes e o tráfico de drogas, armas e pessoas; a condição da mulher e das crianças em zonas de conflito; os impactos de uma ditatura sobre nações; a ascensão de grupos extremistas; o papel da mídia; as epidemias no/do mundo; o terrorismo e o uso das redes sociais por estes grupos; a questão dos invisíveis de nossa sociedade, entre tantos outros que enriqueceram a compreensão de mundo de todos os atores ali envolvidos.

Dessa forma, foi possível constituir traços com o passado e o presente, mostrando a diversidade que encontramos no mundo e que o fizeram como é, e o mais importante, demonstrando que esse caminho não é o único possível, mas apenas um entre tantos que coexistem na constituição do Espaço Geográfico.

Após o fim deste período, os alunos que aprovaram os encontros e a proposta do grupo do livro, propuseram ao professor que continuassem a se encontrar, mas que agora cada um indicaria um livro de que gosta para um dos colegas.

Tal ação será desenvolvida nos últimos dois meses do ano corrente (novembro e dezembro de 2017), seguindo-se a mesma metodologia utilizada anteriormente: escolha de uma obra; construção de uma biografia do autor; contexto em que a obra foi escrita; apresentação das "descobertas".

\section{O CONCEITO DE ESPAÇO MENTALMENTE PROJETADO E A LITERATURA: encontros}

A Geografia carrega em si um alto teor de ausências, o que talvez nenhuma outra ciência (talvez a Física com seu mundo de partículas subatômicas e a Química com suas moléculas) tenha quando reparado seu objeto de estudo, no nosso caso o Espaço Geográfico.

Conforme o Guia de Livros Didáticos do Ensino Fundamental: Anos Finais - Geografia 2017:

A Geografia, em sua essência, fala do não-eu. Do outro. Do outro município que não o meu. Do outro Estado que não o meu. De outro país que não o meu. De outro continente que não o meu. De outra religião, etnia, geração, classe social, dentre outras dimensões, que não a minha (BRASIL, 2016, p.12).

Faz parte da nossa alçada trabalhar com questões que ao mesmo tempo não nos pertence, mas que fazem parte do nosso cotidiano, uma vez que, o espaço geográfico de hoje se organiza a partir de tensões e contradições que nascem em territórios que não o meu. Falamos e vivenciamos no ensino da Geografia Escolar uma série de dimensões escalares, que como uma teia de relações, se costuram para organizar espacialmente as sociedades humanas que formam este planeta que chamamos de Terra.

O primeiro ponto quando pensamos na Geografia, são seus aspectos visíveis e na concretude das coisas, mas se pararmos para refletir, se queremos compreender o que se encontra aparente, precisamos perceber as ausências que ali se englobam.

Isso decorre por razões que vão de aspectos econômicos, como a variação do preço de algum commodities plantado em um território que os do "Norte" chamam de Terceiro Mundo; ao impacto climático ocasionado pelo aquecimento global. 
Bem como as massas de ar não respeitam fronteiras, os conflitos armados em determinados territórios (como a Guerra Civil na Síria; a existência do Estado Islâmico, por exemplo) não apresentam uma causa única de origem e não somente impactam as parcelas territoriais próximas. São frutos de um contexto histórico-geográfico que se liga profundamente aos períodos de exploração das relações metrópoles-colônias que ainda persistem com outras roupagens.

Portanto, para compreender pontos estratégicos como conflitos armados pelo mundo e a questões climáticas de determinadas parcelas territoriais, precisasse desenvolver o pensamento para além do que se encontra posto, é necessário pensar nas ausências que ali persistem e configuram a fisionomia das paisagens.

Professores e alunos são levados a construir visões deste Espaço Geográfico que ao mesmo tempo são distantes, que falam do não-eu, mas que impactam em nossas vidas, sejam em nosso cotidiano como em questões meramente econômicas, sejam em avaliações como provas e trabalhos escolares que precisam ser refletidos e debatidos.

O espaço ausente a que me refiro e um espaço não presente entre as classes que
separam nossos alunos, e um espaço que o aluno tem em seu pensamento, em sua
ideia. O espaço ausente e aquele que o aluno aprende sem nunca ter estado lá, "pior"
e que ele existe, mas não na experiência dos nossos alunos. Este espaço e mentalmente
projetado, ou seja, o aluno e capaz de projetar utilizando-se de diferentes coordenadas
ou de diferentes planos para explicar acontecimentos que se passam nas relações
travadas pelos elementos ou objetos que os compõem (COSTELLA, 2017, p.189).

Massey (2013, p.35) em seu livro comenta uma passagem de sua infância que nos aproxima do que queremos com o conceito de Espaço Mentalmente Projetado. Ao imaginar o que ocorria "lá", ela ia pouco a pouco construindo um Espaço Geográfico em sua mente, sendo capaz de instituir características e aspectos daqueles espaços em que ela se relacionava mesmo que de forma ausente. Naquele seu movimento de viajar mentalmente, ela movia-se sobre diversas trajetórias que se inseriam em um contexto maior do que a nossa própria vivência.

Quando eu era criança, costumava brincar girando um globo terrestre ou folheando
rapidamente um mapa e, abaixando um dedo, tocava um lugar, sem olhar para onde.
Se ele tocasse terra, eu tentava imaginar o que estava acontecendo "lá" "então". Como
as pessoas viviam a paisagem, qual era a hora do dia e qual a estação do ano. Meu
conhecimento era extremamente rudimentar, mas eu era completamente fascinada
pelo fato de que todas essas coisas estavam acontecendo naquele momento, enquanto
eu estava ali, em Manchester, na cama.

Esse mesmo movimento de viagem mental encontra seio na Literatura. As obras de autores atemporais como George Orwell e Aldous Huxley permitem que construamos espaços que não vivenciamos de forma direta, mas que "existem" em outras configurações. O mesmo ocorre com histórias "mais concretas", como as obras de Chang e Nepomuceno, em que uma realidade distante até certo ponto a vida de nossos alunos, acabam por (re)configurar o território em que eles vivem.

Como destaca Costella (2008, p.38):

Espaço Mentalmente Projetado é um termo utilizado pela teoria que compreende a forma ou a maneira como o aluno, sujeito da análise, pode enxergar um espaço que está em sua mente, no seu imagético, por meio de ações e coordenações de ações diante de conceitos que compreendem um espaço ausente concretamente, mas presente em sua capacidade de projetar. 
As histórias que nos levam a outras distâncias, nos permitem viajar sem sair do lugar, ganham um contorno colorido para se compreender o Espaço Geográfico que é o objeto maior de estudo da Geografia Escolar. O nosso imaginário carrega muito da nossa Geografia, como bem destacado por Silva $(2014$, p.34) "há sempre uma parte de imaginário na narrativa geográfica. Há sempre algo de geografia no imaginário".

Desta forma, a compreensão do Espaço Mentalmente Projetado que por consequência encontra consonância da apreensão do Espaço Geográfico, encontra potencialidades no campo literário, que em sua essência carrega um pouco da poesia do mundo, ao mesmo tempo que demonstra com vigor as realidades que ajudam compor a teia colorida de relações do que denominamos de sociedade humana.

\section{ABREVIAÇÕES TEMPORÁRIAS: por mais Elianes}

Dentro do contexto educacional, precisamos pensar por processos que nos faça alcançar o olhar de mais Elianes da história que abriu este texto. São tantas crianças que não compreendem a Geografia Escolar, não encontrando sentido ali, pois não há consonâncias com seu cotidiano.

Concordamos com Couto (2017, p.217) quando este destaca que "o domínio da leitura e da escrita são armas indispensáveis, exigentes, na escola, de opções variadas de leitura", portanto, vemos dentro de obras literárias um ganho para se ensinar a Geografia Escolar.

Durante os quatro meses de projeto, foi perceptível um maior grau de desenvoltura durante os debates das aulas de Geografia e de outros componentes curriculares, em que os alunos passaram a se posicionar com maior frequência sobre os conteúdos trabalhados, até mesmo citando parte das obras lidas durante os encontros.

O espaço de socialização propiciado pelo grupo gerou novas amizades, expandindo o grupo social dos alunos envolvidos, uma vez que juntou em um mesmo espaço estudantes de diferentes turmas e anos.

A professora Freitag (1984) em seu estudo com crianças inseridas em distintas realidades, apontou que a socialização propiciada no ambiente escolar é um dos componentes que facilitam o desenvolvimento do pensamento dos alunos. Dessa forma, contextos como a construção de um grupo de leituras pode facilitar o desenvolvimento do pensamento destes jovens com quem dialogamos diariamente, uma vez que, oferta um espaço de debate que pode auxiliar no combate de um ensino anacrônico e factual da realidade.

Neste contexto vale citar o Plano Nacional de Educação (2014, p.35) que apresenta vinte metas para se melhorar a educação brasileira, entre elas é importante destacar a meta número nove:

Elevar a taxa de alfabetização da população com 15 (quinze) anos ou mais para 93,5\% (noventa e três inteiros e cinco décimos por cento) até 2015 e, até o final da vigência deste PNE, erradicar o analfabetismo absoluto e reduzir em 50\% (cinquenta por cento) a taxa de analfabetismo funcional ${ }^{4}$.

Mesmo após quase duzentos anos da independência de nosso país, ainda falamos em erradicar o analfabetismo, mesmo sendo uma das dez maiores economias do mundo, (dá para acreditar nisso? Parece mais história para colocar medo em criança pequena!) ainda temos pessoas que não sabem nem ler nem escrever... pior... temos universitários considerados como analfabetos funcionais, ou seja, não conseguem compreender plenamente textos que leem. Freitag (1984, p.224) afirma que: 
regras sociais que regem e determinam o convívio em sociedade, perceber problemas e buscar soluções adequadas.

Por isso, as obras literárias ganham potencialidades não somente para compreensão do Espaço Geográfico, mas também, para combater pontos de tamanha complexidade, como terminar com os analfabetos funcionais que dificultam - se não impedem - a construção de uma sociedade alicerçada em preceitos de igualdade dos mais distintos gêneros.

O professor, seja de Geografia, seja de outra área de conhecimento, precisa se colocar em movimento, partir dos saberes espaciais de seus alunos para propor problemas geográficos que precisam ser pensados, refletidos, debatidos e resolvidos dentro do contexto de aprendizagem dos conteúdos dos currículos escolares, permitindo que o aluno compreenda suas práticas espaciais e os pontos de vista de seus colegas e familiares, e, principalmente de outros povos que juntos a ele formam a sociedade humana, sendo a Literatura uma boa pedra angular para essa tarefa.

Para concluir, fazemos nossas as palavras de Azevedo; Martins (2011, p.29-30)

Temos consciência que esta actividade não esgota tudo o que pode ser feito para replicar, num outro contexto, o prazer que cada um de nós sente quando, sem exigir nada em troca, se entrega aos passeios nos chamados bosques da ficção e, embrenhando-se por veredas múltiplas e, por vezes, sinuosas, enceta uma viagem que nos faz transcender as limitações do tempo e do espaço. Temos igualmente consciência que há ainda muito a fazer e que só através de um comprometimento colectivo de todos os actores envolvidos no projecto educativo este empreendimento poderá ser alcançado.

Desta forma nos agarrarmos na ficção não tão irreal que os livros nos concedem para complementar a leitura do espaço geográfico que aprendemos em espaços como a própria sala de aula e em outros ambientes que potencializam essa leitura como museus e teatros, por exemplo. Ao não exigirmos nada da literatura é que nos surpreendemos com uma viagem prazerosa pelo mundo das letras, que juntamente a uma pausa na correria do dia a dia, nos ajuda desenhando na coletividade a compreensão deste mundo que habitamos e construímos enquanto sociedade.

\section{NOTAS}

1 - Ao longo deste texto utilizamos os termos "a criança", "as crianças", "o aluno" e "os alunos" para referirmo-nos genericamente às meninas e aos meninos, sem indicar, em cada caso, os dois sexos (a/o menina/o), o que tende a deixar a leitura mais confusa.

2 - Informações disponíveis no texto "O Brasil para inglês ver (2)" de Luiz Ruffato, encontrado em: https://brasil.elpais.com/brasil/2014/05/05/opinion/1399293712_642432.html. Acesso em: 01 de nov. de 2017.

3 - Informações disponíveis no texto " $44 \%$ da população brasileira não lê e $30 \%$ nunca comprou um livro, aponta pesquisa Retratos da Leitura" de Maria Fernanda Rodrigues. encontrado em: http://cultura.estadao.com.br/blogs/babel/44-da-populacao-brasileira-nao-le-e30-nunca-comprou-um-livro-aponta-pesquisa-retratos-da-leitura/. Acesso em: 01 de nov. de 2017. 
4 - PNE disponível em: <pne.mec.gov.br/images/pdf/pne_conhecendo_20_metas.pdf>. Acesso em: 27 de out. de 2017.

\section{REFERÊNCIAS BIBLIOGRÁFICAS}

ADDARIO, Lynsey. É isso que eu faço: uma vida de amor e guerra. tradução Andrea Gottlieb de Castro Neves. Rio de Janeiro: Intrínseca, 2016.

AZEVEDO, Fernando; MARTINS, Jorge. Formar leitores no Ensino Básico: a mais-valia da implementação de um Clube de Leitura. In: Revista da Investigação às Práticas: Estudos de Natureza Educacional, Lisboa, v.1, n. 1, p.24-35, 2011. Disponível em: <https://ojs.eselx.ipl.pt/index.php/invep/article/view/53>. Acesso em: 01 de nov. 2017.

BECKER, Fernando; MARQUES, Tania Beatriz Iwaszko (Org.). Ser professor é ser pesquisador. 3. ed. Porto Alegre: Mediação, 2012.

BRUM, Eliane. A vida que ninguém vê. Porto Alegre: Arquipélago Editorial, 2006.

CHANG, Leslie T. As garotas da fábrica: da aldeia à cidade, numa China em transformação. tradução Clóvis Marques. Rio de Janeiro: Intrínseca, 2010.

COSTELLA, Roselane Zordan. O significado da construção do conhecimento geográfico gerado por vivências e por representações espaciais. 2008. $202 \mathrm{f}$. Tese (Doutorado em Geografia) - Universidade Federal do Rio Grande do Sul, Porto Alegre, 2008.

COSTELLA, Roselane Zordan. Nas entrelinhas do Livro Didático: a voz e a visibilidade do aluno. In: TONINI, Ivaine Maria; GOULART, Ligia Beatriz; SANTANA FILHO, Manoel Martins de; MARTINS, Rosa Elisabete Militz Wypyczynski; COSTELLA, Roselane Zordan (Org.). O Livro Didático de Geografia e os desafios da docência para aprendizagem. Porto Alegre: Sulina, 2017. p.177-190.

COUTINHO, Clara Pereira; SOUSA, Adão; DIAS, Anabela; BESSA, Fátima; FERREIRA, Maria José Rodrigues Cunha; VIEIRA, Sandra Regina. Investigação-acção: metodologia preferencial nas práticas educativas. In: Revista Psicologia, Educação e Cultura, Lisboa, v.13, n.2, p.355-379, 2009. Disponível em: <http://hdl.handle.net/1822/10148>. Acesso em 22 de out. de 2017.

COUTO, Marcos Antônio Campos. Para a crítica da Geografia que se ensina através dos Livros Didáticos. In: TONINI, Ivaine Maria; GOULART, Ligia Beatriz; SANTANA FILHO, Manoel Martins de; MARTINS, Rosa Elisabete Militz Wypyczynski; COSTELLA, Roselane Zordan (Org.). O Livro Didático de Geografia e os desafios da docência para aprendizagem. Porto Alegre: Sulina, 2017. p.191-220.

COUTO, Mia. Terra Sonâmbula. São Paulo: Companhia de Bolso, 2015.

DEFOE, Daniel. Um diário do ano da peste. tradução Eduardo San Martin. 3. ed. Curitiba: Artes e Ofícios, 2014. 
ERELLE, Anna. Na pele de uma jihadista: a história real de uma jornalista recrutada pelo Estado Islâmico. tradução Dorothée de Bruchard e Eduardo Brandão. São Paulo: Paralela, 2015.

FREIRE, Madalena. Aspectos pedagógicos do construtivismo pós-piagetiano - II. In:

GROSSI, Esther Pillar; BORDIN, Jussara (Org.). Construtivismo pós-piagetiano: um novo paradigma sobre a aprendizagem. 4. ed. Rio de Janeiro: Vozes, 1993. p.162-167.

FREITAG, Bárbara. Sociedade e consciência: um estudo piagetiano na favela e na escola. São Paulo: Cortez Editora, 1984.

GALEANO, Eduardo. As veias abertas da América Latina. tradução de Sergio Faraco. Porto Alegre: L\&PM, 2014.

GALEANO, Eduardo. O livro dos abraços. tradução de Eric Nepomuceno. 2. ed. Porto Alegre: L\&PM, 2014.

HERR, Michael. Despachos do front. tradução Ana Maria Bahiana. Rio de Janeiro: Objetiva, 2005.

HUGO, Victor. Os miseráveis: texto integral. tradução Regina Célia de Oliveira. São Paulo: Martin Claret, 2007.

HUXLEY, Aldous. Admirável mundo novo. tradução Lino Vallandro Vidal Serrano. 22. ed. São Paulo: Globo, 2014.

JESUS, Carolina Maria de. Quarto de despejo: diário de uma favelada. São Paulo: Abril Educação, 2013.

KAERCHER, Nestor André. Pra viajar no cosmos não precisa gasolina: o ensino do Rio Grande do Sul na geografia e as transformações espaciais. In: VERDUM, Roberto; BASSO, Luis Alberto; SUERTEGARAY, Dirce Maria Antunes (Org.). Rio Grande do Sul: paisagens e territórios em transformação. Porto Alegre: Editora da UFRGS, 2004. p. 295-310.

KOESTLER, Arthur. O zero e o infinito. tradução André Pereira da Costa. São Paulo: Amarilys, 2013.

MASSEY, Doreen. Pelo espaço: uma nova política da espacialidade. tradução Hilda Pareto Maciel e Rogério Haesbaert. 4. ed. Rio de Janeiro: Bertrand Brasil, 2013.

NEPOMUCENO, Eric. A memória de todos nós. Rio de Janeiro: Record, 2015.

ORWELL, George. 1984. tradução Alexandre Hubner e Heloisa Jahn. São Paulo: Companhia das Letras, 2009.

ORWELL, George. A revolução dos bichos: um conto de fadas. tradução Heitor Aquino Ferreira. São Paulo: Companhia das Letras, 2007. 
PADURA, Leonardo. O homem que amava os cachorros. tradução Helena Pitta. 2. ed. São Paulo: Boitempo, 2015.

PASSOS, José Meirelles. A noite dos generais: os bastidores do terror militar na Argentina.

2. ed. São Paulo: Editora Brasiliense S.A., 1986.

SANTOS, Leonardo Pinto dos. A construção das relações do espaço ausente na geografia escolar. 2015. 196 f. Dissertação (Mestrado em Geografia) - Instituto de Geociências, UFRGS, 2015.

SANTOS, Leonardo Pinto dos. A Geografia escolar: o espaço mentalmente projetado (EMP), a criança e o pensamento formal - uma breve introdução. In: OLIVEIRA, Tarcísio Dorn de (Org.). Educação, espaço construído e tecnologias: reflexões, desafios e perspectivas. Curitiba: CRV, 2017. p.37-50.

SHUYUN, Sun. A longa marcha: a história do mito fundador da China comunista. tradução Caroline Chang. Porto Alegre: Arquipélago Editorial, 2007.

SILVA, Juremir Machado da. As tecnologias do imaginário. 3. ed. Porto Alegre: Editora Sulina, 2012.

SILVA, Juremir Machado da. O imaginário da Geografia e a Geografia do imaginário. In: GIORDANI, Ana Claudia; TONINI, Ivaine Maria; COSTELLA, Roselane Zordan; CASTROGIOVANNI, Antonio Carlos; KAERCHER, Nestor André (Org.). Aprender geografia: a vivência como metodologia. Porto Alegre: Evangraf, 2014. p.31-36.

SILVA, Juremir Machada da. Raízes do conservadorismo brasileiro: a abolição na imprensa e no imaginário social. 2. ed. Rio de Janeiro: Civilização Brasileira, 2017.

TEEGE, Jennifer. Amon: meu avô teria me executado. tradução Petê Rissatti. Rio de Janeiro: Agir, 2014.

VARELLA, Drauzio. Estação Carandiru. São Paulo: Companhia das Letras, 2005.

WLADYSLAW, Szpilman. O pianista. tradução Thomasz Barcinski. Rio de Janeiro: Edições Bestbolso, 2008. 